\title{
Relationship between maternal methadone dose at delivery and neonatal abstinence syndrome.
}

\author{
Neil S., Seligman \\ Thomas Jefferson University \\ Christopher V. Almario \\ Thomas Jefferson University \\ Edward J. Hayes \\ Thomas Jefferson University \\ Kevin C. Dysart \\ Thomas Jefferson University \\ Follow this and additional works at: https://jdc.jefferson.edu/obgynfp \\ Vincenzo Berghella \\ JPlatisofetfersontediniversitidl Gynecology Commons \\ Let us know how access to this document benefits you
}

See next page for additional authors

\section{Recommended Citation}

Seligman, Neil S.; Almario, Christopher V.; Hayes, Edward J.; Dysart, Kevin C.; Berghella, Vincenzo; and Baxter, Jason K., "Relationship between maternal methadone dose at delivery and neonatal abstinence syndrome." (2010). Department of Obstetrics and Gynecology Faculty

Papers. Paper 16.

https://jdc.jefferson.edu/obgynfp/16

This Article is brought to you for free and open access by the Jefferson Digital Commons. The Jefferson Digital Commons is a service of Thomas Jefferson University's Center for Teaching and Learning (CTL). The Commons is a showcase for Jefferson books and journals, peer-reviewed scholarly publications, unique historical collections from the University archives, and teaching tools. The Jefferson Digital Commons allows researchers and interested readers anywhere in the world to learn about and keep up to date with Jefferson scholarship. This article has been accepted for inclusion in Department of Obstetrics and Gynecology Faculty Papers by an authorized administrator of the Jefferson Digital Commons. For more information, please contact: JeffersonDigitalCommons@jefferson.edu. 


\section{Authors}

Neil S., Seligman; Christopher V. Almario; Edward J. Hayes; Kevin C. Dysart; Vincenzo Berghella; and Jason K. Baxter 


\title{
As submitted to:
}

\section{Journal of Pediatrics}

\author{
And later published as:
}

\section{“RELATIONSHIP BETWEEN MATERNAL METHADONE}

DOSE AT DELIVERY

\section{AND NEONATAL ABSTINENCE SYNDROME"}

\section{Volume 157, Issue 3, 2010, Pages 428-433+433.e 1 DOI: 10.1016/j.jpeds.2010.03.033}

Neil S. Seligman, MD ${ }^{1}$; Christopher V. Almario, MD ${ }^{1}$; Edward J. Hayes, MD MSCP'; Kevin C. Dysart, $\mathrm{MD}^{2}$; Vincenzo Berghella, MD ${ }^{1}$; Jason K. Baxter, MD MSCP${ }^{1}$

${ }^{1}$ Division of Maternal-Fetal Medicine, Department of Obstetrics and Gynecology, Jefferson Medical College of Thomas Jefferson University, Philadelphia, PA

${ }^{2}$ Department of Pediatrics, Jefferson Medical College of Thomas Jefferson University/Nemours Foundation, Philadelphia, PA

Corresponding Author:

Neil S. Seligman, MD

Thomas Jefferson University 
Department of Obstetrics and Gynecology

834 Chestnut Street, Suite 400

Philadelphia, PA 19107

Phone: (215) 955-7996

Email: n.seligman@hotmail.com

\section{Funding: None}

Running Foot: Methadone and neonatal abstinence syndrome 
Seligman

\section{PRECIS}

No correlation was found between maternal methadone dose and rate of neonatal abstinence syndrome among 388 neonates exposed to doses up to $340 \mathrm{mg} /$ day. 
OBJECTIVE: To estimate the relationship between maternal methadone dose and the incidence of neonatal abstinence syndrome (NAS).

METHODS: We performed a retrospective cohort study of pregnant women treated with methadone for opiate addiction who delivered a live-born neonate between 1996 and 2006. Four dose groups, based on total daily methadone dose, were compared $(\leq 80 \mathrm{mg} / \mathrm{d}, 81-120 \mathrm{mg} / \mathrm{d}, 121-$ $160 \mathrm{mg} / \mathrm{d}$, and $>160 \mathrm{mg} / \mathrm{d}$ ). The primary outcome was treatment for NAS. Symptoms of NAS were objectively measured using the Finnegan scoring system and treatment was initiated for a score of $\geq 24$ during the prior 24 hours.

RESULTS: 330 women treated with methadone and their 388 offspring were included. Average methadone dose at delivery was $116.6 \pm 49.7 \mathrm{mg} / \mathrm{d}$ (range $20-340 \mathrm{mg} / \mathrm{d}$ ). Overall, $68 \%$ of infants were treated for NAS. Among infants exposed to methadone doses of $\leq 80 \mathrm{mg} / \mathrm{d}, 81-$ $120 \mathrm{mg} / \mathrm{d}, 121-160 \mathrm{mg} / \mathrm{d}$, and $>160 \mathrm{mg} / \mathrm{d}$, treatment for NAS was initiated for $68 \%, 63 \%, 70 \%$, and $73 \%$ of neonates, respectively $(p=0.48)$. The rate of maternal illicit opiate abuse at delivery was $26 \%, 28 \%, 19 \%$, and $11 \%$, respectively $(p=0.04)$.

CONCLUSION: No correlation was found between maternal methadone dose and rate of NAS. However, higher doses of methadone were associated with decreased illicit opiate abuse at delivery. 


\author{
Abbreviations: \\ human immunodeficiency virus (HIV) \\ neonatal abstinence syndrome (NAS) \\ urine drug screen (UDS) \\ receiver operating characteristic (ROC) \\ selective serotonin reuptake inhibitor (SSRI) \\ odds ratios (OR) \\ confidence intervals $(\mathrm{CI})$
}




\section{INTRODUCTION}

Methadone has been employed since the early 1970s to treat opiate addiction, and it currently remains the standard treatment for opiate addiction in pregnancy.(1) Benefits of methadone include a reduction in cravings for heroin and drug seeking behavior, which thereby also reduces the risk of infection with hepatitis $\mathrm{C}$ virus and human immunodeficiency virus (HIV), prostitution, and criminal activity.(2) Methadone treatment also protects the fetus from repeated episodes of withdrawal by providing steady maternal opiate levels.(3) Furthermore, comprehensive methadone maintenance programs provide opiate-addicted women with the opportunity to receive essential prenatal care and services that they would otherwise be without.(4) Despite these benefits, methadone treatment is not without controversy, and much of the debate centers on the optimal methadone dose and on its association with neonatal abstinence syndrome (NAS).

One of the earliest reports of the relationship between methadone and neonatal withdrawal was published in 1975 by Rosen et al. The authors found no consistent relationship between maternal methadone dose and the severity of neonatal withdrawal symptoms in this study and a subsequent study in 1976.(5)(6) In the same year, several studies reported the opposite, showing a positive correlation between maternal methadone dose and both the severity of neonatal withdrawal symptoms and the incidence of neonatal withdrawal requiring pharmacologic treatment with maternal methadone doses $<20 \mathrm{mg} / \mathrm{d}$.(7)(8)(9) Of eight published studies, to our knowledge, which include a "low" dose group of $<30 \mathrm{mg} / \mathrm{d} 78 \%$ report a positive correlation between maternal methadone and NAS.(6)(7)(8)(9)(10)(11)(12)(13) Presently, methadone maintenance programs for pregnant women, such as ours, use significantly higher doses to prevent withdrawal. Five out of six (83\%) more recent published studies which use a 
higher cutoff (<50 mg/d or above) to define the "low" dose group report no such association.(14)(15)(16)(17)(18)(19) Yet, despite these and other studies $(20)(21)(22)(23)(24)(25)$ there is still no clear answer. Much of difficulty is due to the considerable methodological variability such as the inclusion of women undergoing withdrawal treatment as opposed to maintenance, insufficient reporting of confounding factors (i.e. polysubstance abuse), and differences in the definition and assessment of NAS (Table 1; online only). With these limitations in mind, our objective was to estimate the relationship between clinically appropriate methadone doses and NAS. 


\section{MATERIALS AND METHODS}

We performed a retrospective review of the outcomes of opiate-addicted women on methadone maintenance who delivered a live-born neonate between September 1996 and June 2006. A full description of our approach to methadone stabilization and maintenance has been previously described elsewhere.(14) The only change in maternal management over the eleven year study period was a small increase (20mg to $30 \mathrm{mg}$ ) in the initial stabilization dose. There were no changes in neonatal assessment or treatment for NAS. No distinction was made between women who conceived while already enrolled in a methadone program and those who became pregnant while on heroin and required initial stabilization during pregnancy.

All neonates were delivered at Thomas Jefferson University Hospital. We excluded infants delivered $<32$ weeks gestation, as signs and symptoms of prematurity can be confused with NAS.(21) Non-viable fetuses delivered before 23 weeks gestation and stillbirths were also excluded. Signs and symptoms of NAS were objectively assessed every eight hours for the first 72 hours of life according to the method described by Finnegan.(25) Treatment for NAS was initiated for a cumulative score $\geq 24$ during the prior 24 hours. The NAS treatment protocol at our institution has been described elsewhere.(26) Data for a portion of the women and neonates has been previously reported.(14)(26)

Exposure to methadone was confirmed by a UDS for methadone. For women who instead had a drug of abuse screen (does not test for methadone), documentation in the medical record of methadone use was necessary for inclusion in the study. The methadone dose at delivery was defined as the total daily methadone dose at the time of delivery. To determine the cohorts, we divided women into four dose groups approximating quartiles; $\leq 80 \mathrm{mg} / \mathrm{d}, 81-120$ $\mathrm{mg} / \mathrm{d}, 121-160 \mathrm{mg} / \mathrm{d}$, and $>160 \mathrm{mg} / \mathrm{d}$. A receiver operator characteristic (ROC) curve was 
used to determine the sensitivity and specificity of various methadone dose cutoffs for predicting NAS ensuring the appropriateness of these dose groups.

All statistical tests were performed with SPSS 17.0 (SPSS Inc., Chicago, IL). The $\chi^{2}$ test, analysis of variance test, and Kruskal-Wallis test were used to analyze categorical, normally distributed continuous, and non-normally distributed continuous variables, respectively. A $p$ value $<.05$ was considered statistically significant. Several women delivered twice during the study period. To adjust for potential confounding and clustering due to women who had more than one pregnancy during the study period, a generalized estimating equation model was used.

For women who delivered after 2000, the database was expanded to include additional variables. The additional information gathered included non-opiate illicit drug abuse at delivery as determined by urine drug screen (UDS), selective serotonin reuptake inhibitor use, alcohol use (by self report), and others. Due to the difference in the amount of variables, two separate multivariate models were fit. The first was termed "limited" in time as it included a larger set of variables which were recorded only for women who delivered between January 2000 and June 2006. The second was deemed "extended" in time as it included fewer variables, but data was available for all women who delivered during the entire 10 year study period (September 1996 and June 2006). For both the "limited" and "extended" adjustments, variables with $\mathrm{p}<0.2$ found through univariate analysis were included as covariates in the generalized estimating equation model to calculate adjusted odds ratios (OR) with $95 \%$ confidence intervals (CI). This study was approved by the Thomas Jefferson University Institutional Review Board. Informed consent was not required for this study. 


\section{RESULTS}

We analyzed outcomes of 330 opiate-addicted women on methadone treatment who had 386 pregnancies from September 1996 to June 2006. Two women had twins, thus our study included 388 neonates. The gestational age at birth was $<32$ weeks for 19 neonates (range 27-31 weeks) excluded from the study. Maternal demographic characteristics are presented in Table 2. Only race differed among dose groups $(p=.04)$. Caucasian women were on higher mean doses of methadone $(122.9 \pm 50.7 \mathrm{mg} / \mathrm{d})$ when compared to non-Caucasian women $(103.5 \pm 44.9 \mathrm{mg} / \mathrm{d}$, $p<.001)$. Psychiatric medications were prescribed to $27 \%$ of women in the methadone maintenance program and $23 \%$ of those women were taking more than one psychiatric medication (data available for 288 pregnancies). The proportion of women in each dose group using prescription psychiatric drugs was not significantly different $(\mathrm{p}=.39)$ but prescription benzodiazepine use (mainly clonazepam) was more common among women on higher doses $(\mathrm{p}=$ $.01)$.

Table 3 presents details of the methadone maintenance program and rates of illicit substance abuse at the time of delivery. Overall, the average methadone dose at delivery was $116.6 \mathrm{mg} / \mathrm{d}$ (range 20-340 mg/d). Timing of methadone stabilization (before or during pregnancy) and rate of re-stabilization (due to non-compliance) was known for 288 pregnancies. Women who conceived on methadone had a higher mean methadone dose at delivery compared to those who were stabilized during pregnancy $(135.3 \pm 55.5 \mathrm{mg} / \mathrm{d}$ vs. $118.5 \pm 48.7 \mathrm{mg} / \mathrm{d} ; \mathrm{p}=$ .01) and a greater proportion of women who conceived on methadone were in higher dose groups. Admissions for re-stabilization were less likely in the higher dose groups as was illicit opiate abuse. Of the 77 women with known prescription psychiatric medication use, 27 (35\%) used illicit drugs at delivery compared to $42(20 \%)$ of the 211 not taking prescription psychiatric 
medications $(\mathrm{p}=.008)$. Women who were initially stabilized on methadone during pregnancy had lower rate of illicit drug abuse at delivery (66 [34\%] vs. 26 [28\%]; p = .36) and illicit opiate abuse at delivery $(11[12 \%]$ vs. 36 [18\%]; $\mathrm{p}=.17)$ but the difference did not reach statistical significance.

Neonates had an average gestational age at delivery of $37.7 \pm 2.2$ weeks. . The rate of preterm birth ( $\geq 32$ weeks and $<37$ weeks) was $27 \%$ (106/388). The mean birth weight and head circumference were $2808 \pm 544 \mathrm{~g}$ and $32.5 \pm 2.1 \mathrm{~cm}$, respectively. No significant differences were found between gestational age at delivery, birth weight, head circumference, and rate of preterm birth among neonates exposed to maternal methadone doses of $\leq 80 \mathrm{mg} / \mathrm{d}, 81-120$ $\mathrm{mg} / \mathrm{d}, 121-160 \mathrm{mg} / \mathrm{d}$, and $>160 \mathrm{mg} / \mathrm{d}($ all $p>.31)$.

Indices of NAS according to maternal methadone dose are included in Table 4. Overall, $262(62 \%)$ neonates required treatment for NAS. There was no significant difference in the incidence of NAS, maximum NAS score, length of neonatal treatment, or maximum dose of neonatal opium solution between difference dose groups. Among women who had more than one pregnancy during the study period, there was a trend toward higher mean methadone doses in the subsequent pregnancy $\left(119 \pm 51.7 \mathrm{mg} / \mathrm{d} 1^{\text {st }}\right.$ pregnancy versus $134 \pm 58.2 \mathrm{mg} / \mathrm{d} 2^{\text {nd }}$ pregnancy; $\mathrm{p}=.18)$ however, there was no difference in the rate of NAS $\left(64 \% 1^{\text {st }}\right.$ pregnancy versus $62 \% 2^{\text {nd }}$ pregnancy; $\mathrm{p}=.83$ ). Even after adjusting for confounding by significant variables $(\mathrm{p}<0.2)$ and the effect clustering due to multiple pregnancies by the same woman, no correlation was found between methadone dose and NAS (Table 5; online only). Additionally, no methadone dose defined a cutoff significantly predictive of NAS using a ROC curve (area $.52 ; \mathrm{p}=.52[95 \% \mathrm{CI} .46-.58])$. In the $\leq 80 \mathrm{mg} / \mathrm{d}$ dose group, only 7 women had a methadone dose at delivery that was $\leq 30 \mathrm{mg} / \mathrm{d}$. In this subgroup, four $(57 \%)$ neonates were treated for NAS 
for $7,30,31$, and 54 days. Compared to women on higher doses, there was no significant difference in the rate of NAS $(\mathrm{p}=1.0)$. The Figure depicts the stable rate of NAS against the reduction in illicit opiate abuse at delivery which is most apparent in the three highest dose groups (Figure).

The rate of NAS was compared between methadone dose groups for selected subpopulations of women (Table 4). NAS was more common among neonates born to women who were initially stabilized on methadone during pregnancy but the difference was not statistically significant $(\mathrm{p}=.18)$. There was no difference in the incidence of NAS between methadone dose groups for either neonates born to women who conceived on methadone or those who were born to women initially stabilized on methadone during pregnancy. Likewise, these was no difference in the incidence of NAS between dose groups for the subpopulations of women abusing illicit opiates at delivery, women whose UDS was negative for illicit opiate abuse at delivery, women who delivered prematurely, and those who delivered at term.

Lastly, we also investigated other variables predictive of NAS (Table 6; online only). Through a univariate analysis, preterm birth, tobacco use, and illicit opiate and cocaine abuse at delivery increased the risk for NAS (Table 5; online only). However, after adjusting for confounding, only preterm birth (adjusted OR 3.0, 95\% CI $1.4-6.1$ ) remained predictive of NAS. Tobacco use had a trend towards increased risk for NAS (adjusted OR 2.2, 95\% CI 0.98 $5.0)$. 


\section{DISCUSSION}

The incidence of NAS in our population was $68 \%$ and is well within the literature's reported range of $30 \%$ to $81 \% .(9)(22)$ Even among neonates born to women prescribed the lowest methadone dose, NAS required treatment in more than half of neonates. In our population, the incidence of NAS requiring pharmacologic treatment does not reflect maternal methadone use in a dose dependent fashion. Furthermore, higher doses of methadone were associated with decreased maternal illicit opiate abuse at delivery.

There is strong physiologic evidence to support our policy of liberal dose increases to decrease maternal withdrawal symptoms. First, physiologic changes throughout pregnancy alter the pharmacokinetics and pharmacodynamics of methadone. Plasma volume is increased leading to an increased volume of distribution. The fraction of oral methadone absorbed is decreased, the half life of methadone decreased (27) secondary to increased hepatic clearance (28)(29), and protein binding is decreased.(30) Additionally, there is a high degree of inter-individual variability in methadone metabolism. Maternal symptomatology more closely reflects serum trough level than dose.(31)(32)

The concentration of methadone crossing the placenta determined by gestational agedependent passive diffusion, P-glycoprotein efflux, and metabolism by placental aromatase. (33)(34)(35)(36) The fetal concentration is then modified by hepatic metabolism, a process which is also gestational age dependent. Ultimately, the expression of opioid withdrawal is dependent on the final neonatal methadone concentration and its interplay with the central nervous system (also gestational age dependent [21]). Even the exact relationship between neonatal methadone levels at birth is unclear $(17)(22)(24)(37)(38)$ and total opioid exposure (methadone plus other illicit opiate abuse) should be factored in as a confounder. Given the 
complex relationship between the mechanisms that determine neonatal dose and expression of NAS, it unlikely an individual woman's methadone dose will reliably predict neonatal outcome.

Most of the women in our study had one or more exposures to tobacco, alcohol, other illicit drugs or prescription medications thought to confound the expression and severity of withdrawal. Both Tobacco and benzodiazepines (prescription or illicit) worsen methadone withdrawal. (14)(20)(26)(39)(40)(41)(42)(43) Likewise, abruption discontinuation of cocaine at birth results in a neonatal toxicity with symptoms that overlap with methadone withdrawal.(39)(44) The effect of each of these exposures was adjusted for in the statistical analysis (Tables 5 and 6).

Neonatal withdrawal from selective serotonin reuptake inhibitors (SSRIs) is a well recognized syndrome (45)(46) that occurs in $22-31.5 \%$ of exposed neonates.(47) The signs and symptoms of SSRI withdrawal overlap considerably with opioid withdrawal and can be measured with the Finnegan scoring system.(47) Additionally, SSRIs may increase methadone concentrations through inhibition of the CYP450 system.(48) While it is possible that SSRI withdrawal confounded the assessment of NAS this effect would have caused a small but equal increase in the incidence of NAS in each group since there was no significant difference in SSRI use. Other studies have also shown that SSRI use does not increase the odds of receiving treatment for NAS (11) or affect the length of treatment.(26)

A significant strength of our study is the large population size. The majority of studies reporting an association between maternal methadone dose and NAS were small studies that included only 70 infants or less.(9)(10)(12)(16)(21)(22) Also, our population includes women prescribed the highest reported doses used in pregnancy. The lowest dose group, $\leq 80 \mathrm{mg} / \mathrm{d}$, may be considered as such compared to studies that used a cutoff of $\leq 30 \mathrm{mg} / \mathrm{d}$. Since our 
methadone stabilization protocol uses an initial stabilization dose of either 20 or $30 \mathrm{mg} / \mathrm{d}$ and the median methadone dose after initial hospital stabilization was $65 \mathrm{mg} / \mathrm{d}$ (range $15-250 \mathrm{mg} / \mathrm{d})(26$ unpublished data) a "very low" dose group (i.e. $<30 \mathrm{mg} / \mathrm{d}$ ) would be impractical. Furthermore, the large population size and wide dose range included in our study allowed us to compare the rate of NAS between four near-equal sized dose groups inclusive of all previously published cutoffs, as opposed to just comparing "high" and "low" dose groups as many previous studies have done.

Another important strength of our research was the choice to use NAS requiring pharmacologic treatment, based on Finnegan score, as the primary outcome. The use of an objective outcome is especially important since, as in most studies, the neonatologists were not blinded to maternal methadone dose. Instead, other studies chose to use presence or severity of withdrawal symptoms (8)(9)(24) or used NAS requiring pharmacologic treatment measured by novel scoring systems. We contend that NAS requiring treatment determined by a recognized NAS scoring system (Finnegan [25], Lipsitz [49], Rivers [50]) is the most appropriate outcome measure for studying neonatal withdrawal due to in utero methadone exposure. Most neonates experience at least some symptoms of withdrawal but neonates that do not require treatment are discharged home after three days as opposed to an average of 30 days when treatment is necessary.(26) Readmission after 72 hours for withdrawal or dehydration is a possibility that was not analyzed. However, of the approximately $30 \%$ of neonates who are discharged without treatment for NAS and whose mothers are following up at the Family Center methadone treatment program, readmission is rare according to the neonatologists (Dysart) at our hospital.

This study evaluated the outcomes of neonates delivered over an 11 year period. Although practice changes over time, save for a marginal difference in the initial methadone 
stabilization dose (20 mg/d (14) versus $30 \mathrm{mg} / \mathrm{d}$ (26), there were no other changes in either maternal or neonatal management during that interval. Another limitation is the expansion of the type and amount of data included in the database. Consistency in the data collected over the two periods was verified by carefully comparing the data dictionaries from both periods. We did not consider the effect of breastfeeding, as such data was unavailable. The importance of breastfeeding in preventing NAS remains controversial.(11)(16)(40)(51) The concentration of methadone in breast milk is low (52) and although the absolute concentration is dose dependent, is unlikely to be sufficient to prevent withdrawal.(53)

The best measure of the adequacy of methadone treatment is cessation of illicit opiate abuse. In our study, only $11 \%$ of women taking $>160 \mathrm{mg} / \mathrm{d}$ of methadone also abused illicit opiates at the time of delivery versus $27 \%$ of women who took $\leq 120 \mathrm{mg} / \mathrm{d}$. McCarthy et al noted similar findings, as only $11 \%$ of infants from their high dose methadone group $(\geq 100$ $\mathrm{mg} / \mathrm{d}$ ) were positive for illicit drugs compared to $27 \%$ of infants from their low dose group (< $100 \mathrm{mg} / \mathrm{d}) .(18)$ The benefits of methadone maintenance include cessation of illegal activities, avoidance of infectious diseases, and participating in prenatal care. Therefore, preventing continued drug abuse by providing therapeutic doses would seem far more important than using low methadone doses to theoretically reduce the incidence of NAS, which when treated appropriately has not been demonstrated to have any untoward effects.(3)

Our findings provide compelling evidence that no correlation exists between maternal methadone dose and rate of NAS. Reducing maternal methadone doses to theoretically lower the risk for NAS appears unwarranted. Instead, the goal of the clinician should be to administer doses of methadone that adequately control maternal withdrawal symptoms and reduce drug cravings. In the future, a randomized, double blinded study to validate our results in which in 
one group women are restricted to a certain dose while the ones in the other group aren't would be ideal. There may be ethical concerns over restricting dose and possibly subjecting both the mother and fetus to withdrawal as this would constitute detoxification. In our opinion, an adequately powered prospective trial with both the physician prescribing methadone and the pediatrician blinded to dose, an objective measurement of NAS, and controlling for known confounders would probably be a viable alternative. 


\section{REFERENCES}

1. National Consensus Development Panel on Effective Medical Treatment of Opiate Addiction. Effective medical treatment of opiate addiction. JAMA 1998; 280:1936-43.

2. Wilbourne P, Wallerstedt C, Dorato V, Curet LB. Clinical management of methadone dependence during pregnancy. J Perinat Neonatal Nurs 2001; 14:26-45.

3. Kaltenbach K, Berghella V, Finnegan L. Opioid dependence during pregnancy. effects and management. Obstet Gynecol Clin North Am 1998; 25:139-51.

4. Finnegan LP. Treatment issues for opioid-dependent women during the perinatal period. J Psychoactive Drugs 1991; 23:191-201.

5. Rosen TS and Pippenger CE. Disposition of methadone and its relationship to severity of withdrawal and the newborn. Addict Dis. 1975;2(1-2):169-78.

6. Rosen TS and Pippenger CE. Pharmacologic observations on the neonatal withdrawal syndrome. J Pediatr 1976; 88:1044-8.

7. Madden JD, Chappel JN, Zuspan F, Gumpel J, Mejia A, Davis R. Observation and treatment of neonatal narcotic withdrawal. Am J Obstet Gynecol 1977; 127:199-201.

8. Ostrea EM, Chavez CJ, Strauss ME. A study of factors that influence the severity of neonatal narcotic withdrawal. J Pediatr 1976; 88:642-5.

9. Strauss ME, Andresko M, Stryker JC, Wardell JN. Relationship of neonatal withdrawal to maternal methadone dose. Am J Drug Alcohol Abuse 1976; 3:339-45.

10. Dashe JS, Sheffield JS, Olscher DA, Todd SJ, Jackson GL, Wendel GD. Relationship between maternal methadone dosage and neonatal withdrawal. Obstet Gynecol 2002; 100:1244-9. 
11. Dryden C, Young D, Hepburn M, Mactier H. Maternal methadone use in pregnancy: factors associated with the development of neonatal abstinence syndrome and implications for healthcare resources. BJOG. 2009;116:665-71.

12. Malpas TJ, Darlow BA, Lennox R, Horwood LJ. Maternal methadone dosage and neonatal withdrawal. Aust N Z J Obstet Gynaecol 1995; 35:175-7.

13. Shaw NJ and McIvor L. Neonatal abstinence syndrome after maternal methadone treatment. Arch Dis Child Fetal Neonatal Ed 1994; 71:F203-5.

14. Berghella V, Lim PJ, Hill MK, Cherpes J, Chennat J, Kaltenbach K. Maternal methadone dose and neonatal withdrawal. Am J Obstet Gynecol 2003; 189:312-7.

15. Brown HL, Britton KA, Mahaffey D, Brizendine E, Hiett AK, Turnquest MA. Methadone maintenance in pregnancy: A reappraisal. Am J Obstet Gynecol 1998; 179:459-63.

16. Lim S, Prasad MR, Samuels P, Gardner DK, Cordero L. High-dose methadone in pregnant women and its effect on duration of neonatal abstinence syndrome. Am J Obstet Gynecol 2009; 200:70.e1,70.e5.

17. Kuschel CA, Austerberry L, Cornwell M, Couch R, Rowley RS. Can methadone concentrations predict the severity of withdrawal in infants at risk of neonatal abstinence syndrome? Arch Dis Child Fetal Neonatal Ed 2004; 89:F390-3.

18. McCarthy JJ, Leamon MH, Parr MS, Anania B. High-dose methadone maintenance in pregnancy: Maternal and neonatal outcomes. Am J Obstet Gynecol 2005; 193:606-10.

19. Stimmel B, Goldberg J, Reisman A, Murphy RJ, Teets K. Fetal outcome in narcoticdependent women: The importance of the type of maternal narcotic used. Am J Drug Alcohol Abuse 1982; 9:383-95. 
20. Bakskad B, Sarfi M, Welle-Strand GK, Randval E. Opioid Maintenance Treatment during Pregnancy: Occurrence and Severity of Neonatal Abstinence Syndrome. Eur Addict Res. 2009; $15: 128-134$.

21. Doberczak TM, Kandall SR, Wilets I. Neonatal opiate abstinence syndrome in term and preterm infants. J Pediatr 1991; 118:933-7.

22. Doberczak TM, Kandall SR, Friedmann P. Relationship between maternal methadone dosage, maternal-neonatal methadone levels, and neonatal withdrawal. Obstet Gynecol $1993 ; 81: 936-40$.

23. Hagopian GS. Wolfe HM, Sokol RJ, Ager JW, Wardell JN, Cepeda EE. Neonatal outcome following methadone exposure in utero. J Matern Fetal Med 1996;5:348-54.

24. Harper RG, Solish G, Feingold E, Gersten-Woolf NB, Sokal MM. Maternal ingested methadone, body fluid methadone, and the neonatal withdrawal syndrome. Am J Obstet Gynecol 1977; 129:417-24.

25. Finnegan LP, Connaughton JF, Jr., Kron RE, Emich JP. Neonatal abstinence syndrome: assessment and management. Addict Dis 1975; 2(1-2):141-58..

26. Seligman NS, Salva N, Hayes EJ, Dysart KC, Pequignot EC, Baxter JK. Predicting length of treatment for neonatal abstinence syndrome in methadone-exposed neonates. Am J Obstet Gynecol 2008; 199:396.e1,396.e7.

27. Swift Swift RM, Dudley M, Deptrillo P, Camara P, Griffiths W. Altered methadone pharmacokinetics in pregnancy: implications for dosing. J Subst Abuse. 1989;1(4):453-60.

28. Jarvis MA, Wu-Pong S, Kniseley JS, Schnoll SH. Alterations in methadone metabolism during late pregnancy. J Addict Dis. 1999;18(4):51-61. 
29. Wolff K, Boys A, Rostami-Hodjegan A, Hay A, Raistrick D. Changes to methadone clearance during pregnancy. Eur J Clin Pharmacol 2005; 61:763-8.

30. Pond Pond SM, Kreek MJ, Tong TG, Raghunath J, Benowitz NL. Altered methadone pharmacokinetics in methadone-maintained pregnant women. J Pharmacol Exp Ther. $1985 ; 233(1): 1-6$.

31. Drozdick J,3rd, Berghella V, Hill M, Kaltenbach K. Methadone trough levels in pregnancy. Am J Obstet Gynecol 2002; 187:1184-8.

32. Jansson LM, Dipetro JA, Elko A, Jansson MV. Maternal vagal tone change in response to methadone is associated with neonatal abstinence syndrome severity in exposed neonates. $\mathbf{J}$ Matern Fetal Neonatal Med. 2007;20(9):677-85.

33. Deshmukh SV, Nanovskaya TN, Hankins GD, Ahmed MS. N-demethylation of levo-alpha acetylmethadol by human placental aromatase. Biochem Pharmacol. 2004;67(5):855-92.

34. Nanovskaya TN, Deshmukh SV, Nekhayeva IA, Zharikova OL, Hankins GD, Ahmed MS. Methadone metabolism by the human placenta. Biochem Pharmacol. 2004;68(3):583-91.

35. Nekhayeva IA, Nanovskaya TN, Deshmukh SV, et al., Bidirectional transfer of methadone across human placenta. Biochemical Pharmacology 2005;69(1):187-97.

36. Nanovskaya TN, Nekhayeva IA, Hankins GDV, Ahmed MS. Transfer of methadone across the dually perfused preterm human placental lobule. Am J Obstet Gynecol. 2008;198:126e1$126 \mathrm{e} 4$.

37. Blinick Blinick G, Wallach RC, Jerez E. Pregnancy in narcotics addicts treated by medical withdrawal. The methadone detoxification program. Am J Obstet Gynecol. 1969;105(7):997-1003.

38. Mack G, Thomas D, Giles W, Buchanan N. Methadone levels and neonatal withdrawal. J Paediatr Child Health. 1991 Apr;27(2):96-100. 
39. AAP American Academy of Pediatrics Committee on Drugs: Neonatal Drug Withdrawal. Pediatrics. 1998;101(6):1079-88.

40. Abdel-Latif ME, Pinner J, Clews S, Cooke F, Lui K, Oei J. Effects of breast milk on the severity and outcome of neonatal abstinence syndrome among infants of drug-dependent mothers. Pediatrics 2006; 117:e1163-9

41. Choo Choo RE, Huestis MA, Schroeder JR, Shin AS, Jones HE. Neonatal abstinence syndrome in methadone-exposed infants is altered by level of prenatal tobacco exposure. Drug Alcohol Depend. 2004;75(3):253-60.

42. Oei $\mathbf{J}$ and Lui K. Management of the newborn infant affected by maternal opiates and other drugs of dependency. J Paedriatr child Health. 2007;43(1-2):9-18.

43. Sutton LR and Hinderliter SA. Diazepam abuse in pregnant women on methadone. Implications for the neonate. Clin Pediatr (Phila). 1990;29(2):108-11.

44. Finnegan L, Kaltenbach K, Weiner S, Haney B. Neonatal cocaine exposure: assessment of risk scale. Pediatr Res. 1990;27:10A

45. ACOG Practice Bulletin \#92: Use of Psychiatric Medications During Pregnancy and Lactation. Obstet Gynecol. 2008;111(4):1001-20.

46. Sanz EJ, Cuevas CD, Kiuru A, Bate A, Edwards R. Selective serotonin reuptake inhibitors in pregnant women and neonatal withdrawal syndrome: a database analysis. Lancet. 2005;365:482-87.

47. Levinson-Castiel R, Merlob P, Linder N, Sirota L, Klinger G. Neonatal Abstinence Syndrome After In Utero Exposure to Selective Serotonin Reuptake Inhibitors in Term Infants. Arch Pediatr Adolesc Med. 2006;160:173-76. 
48. McCance-Katz EF, Rainey PM, Smith P, Morse GD, Friedland G, Boyarsky B, Gourevitch M, Jatlow P. Drug interactions between opioids and antiretroviral medications: interaction between methadone, LAAM, and delavirdine. Am J Addict. 2006 Jan-Feb;15(1):23-34.

49. Lipsitz Lipsitz PJ. A proposed neonatal withdrawal score for use with newborn infants: A pragmatic evaluation of its efficacy. Clin Pediatr. 1975;14(6):592-4.

50. Rivers RP. Neonatal opiate withdrawal. Arch Dis Child. 1986;61(12):1236-9.

51. Jansson LM, Choo R, Velez ML, Harrow C, Schroeder JR, Shakleya DM et al. Methadone maintenance and breastfeeding in the neonatal period. Pediatrics 2008; 121:106-14.

52. Kreek MJ. Methadone disposition during the perinatal period in humans. Pharmacol Biochem Behav. 1979;11 Suppl:7-13.

53. Begg EJ, Malpas TJ, Hackett PL, Ilett KF. Distribution of R- and S-methadone into human milk during multiple, medium to high oral dosing. J Clin Pharmacol. 2001;52:681-5. 
Figure. Rates of neonatal abstinence syndrome and maternal illicit opiate abuse at delivery according to methadone dose 